\title{
DEVELOPMENT AND VALIDATION OF REVERSE-PHASE HIGH-PERFORMANCE LIQUID CHROMATOGRAPHY METHOD FOR SIMULTANEOUS ESTIMATION OF OLANZAPINE AND ARIPIPRAZOLE IN SYNTHETIC MIXTURES
}

\author{
MEGHA PATEL ${ }^{1 *}$, PARESH PATEL ${ }^{2}$, DHARA PATEL $^{3}$ \\ ${ }^{1}$ Department of Pharmacy, Ganpat University, Kherva, Gujarat, India. ${ }^{2}$ Department of Pharmaceutical Chemistry, Ganpat University, \\ Kherva, Gujarat, India. ${ }^{3}$ Department of Pharmaceutical Quality Assurance, Pioneer Pharmacy Degree College, Vadodara, Gujarat, India. \\ Email: patel.dhara.j@gmail.com
}

Received: 05 May 2020, Revised and Accepted: 15 June 2020

ABSTRACT

Objective: A simple, rapid, accurate, precise, specific, and sensitive reverse-phase high-performance liquid chromatography (RP-HPLC) method has been developed and validated for simultaneous estimation of olanzapine (OLZ) and aripiprazole (APR) in synthetic mixtures.

Methods: The stationary phase used for chromatographic separation was Phenomenex $\mathrm{C}_{18}$ column $(250 \mathrm{~mm} \times 4.6 \mathrm{~mm}$ i.d, particle size $5 \mu \mathrm{m})$ and mobile phase used for separation was methanol: Phosphate buffer $(\mathrm{pH} 3)$ taken in ratio of 75:25\%v/v. The flow rate was used $1.0 \mathrm{ml} / \mathrm{min}$ at room temperature and drugs detected at $240 \mathrm{~nm}$ with injection volume $20 \mu \mathrm{L}$.

Results: The retention time for OLZ and APR was found to be 4.231 and $6.523 \mathrm{~min}$, respectively. The linearity was performed using a concentration range of $0.5-3.0$ for both drugs. The correlation coefficient was found to be 0.999 for OLZ and APR. The \% purity of both the drug was found to be 98-102\%. The proposed RP-HPLC method has been validated, according to International council on harmonization Q2 (B) guidelines.

Conclusion: There was no interference of any diluents and excipients in the determination of drugs from synthetic mixture. Hence, the developed method can be used for routine quality control analysis.

Keywords: Olanzapine, Aripiprazole, Reverse-phase high-performance liquid chromatography, Validation.

(c) 2020 The Authors. Published by Innovare Academic Sciences Pvt Ltd. This is an open access article under the CC BY license (http://creativecommons. org/licenses/by/4. 0/) DOI: http://dx.doi.org/10.22159/ajpcr.2020.v13i8.38278

\section{INTRODUCTION}

Schizophrenia is a chronic and severe mental confusion affecting 20 million people worldwide. It is characterized by distortion in thinking, sensitivity, emotions, sense of self, and behavioral problems. Common experiences such as hallucinations and delusions and may affect educational and occupational performance. Stigma, discrimination, and violation of the human rights of people with schizophrenia are common [1,2]. Schizophrenia is treatable with medicines and psychosocial support is effective. The psychopharmacological management of therapy-resistant symptoms of schizophrenia is a big challenge for psychiatrists because this dilemma is generally approached with a realistic and polypharmaceutical medical treatment, for which evidence is lacking. There is some proof data that the combination of olanzapine (OLZ) and aripiprazole (APR) has advantages regarding symptoms control and side effects [3-5]. OLZ is a second-generation neuroleptic drug approved by the food and drug administration (USA) for the treatment of psychiatric patients suffering from schizophrenia to bipolar disorder. OLZ (Fig. 1), 2-methyl-4-(4-methylpiperazin-1-yl)-10Hthieno $[2,3-b][1,5]$ benzodiazepine, is a psychotropic agent belonging to the synthetic derivative of thienobenzodiazepine [6]. APR (Fig. 2), (7-[4[4-(2,3-dichlorophenyl)-1-piperazinyl] butoxy]-3, 4-dihydrocarbostyril, is belonging to the chemical class of benzisoxazole derivatives and is indicated for the treatment of schizophrenia [7]. From a deep literature survey, various methods have been reported for the determination of OLZ and APR individually and in combination with other drugs [8-30]. However, the reverse-phase high-performance liquid chromatography (RP-HPLC) method for the simultaneous determination of OLZ and APR in combination has not yet been reported. In the presented research work, RP-HPLC method was developed and validated according to the International council on harmonization (ICH) [31].

\section{METHODS}

Chemicals and reagents

OLZ and APR of pharmaceutical grade were kindly supplied as gift samples by Sun Pharmaceutical Advanced Research Center, Vadodara. Methanol, acetonitrile, and water used were of HPLC grade and purchased from Merck specialist Pvt. Ltd., India. Methanol, potassium dihydrogen orthophosphate, triethylamine, and orthophosphoric acid used were of AR grade.

\section{Instrumentation}

A HPLC system with LC solution data handling system (Shimadzu LC-20 10- Japan) was equipped with injector (Rheodyne, $20 \mu \mathrm{L}$ ), ultraviolet (UV) and PDA detector. The chromatographic analysis was performed using LC solution software on a Phenomenex $\mathrm{C}_{18}$ column $(250 \mathrm{~mm} \times$ $4.6 \mathrm{~mm}$ i.d., particle size $5 \mu \mathrm{m}$ ). Digital weighing balance (Shimadzu ATX 224, Japan), pH meter (Janki Impex Pvt. Ltd.), vacuum filtration assembly and ultrasonic bath cleaner were used during the study.

Standard stock solution preparation of OLZ $(100 \mu \mathrm{g} / \mathrm{mL})$ and APR $(100 \mu \mathrm{g} / \mathrm{mL})$

Ten milligrams of OLZ and $10 \mathrm{mg}$ of APR were weighed accurately and transferred to a $100 \mathrm{ml}$ volumetric flask. This stock solution was prepared in methanol sonicated for $15 \mathrm{~min}$; the volume was adjusted up to the mark with the same solvent. The solution was filtered through Whatman filter paper no 41 . This stock solution contained $100 \mu \mathrm{g} / \mathrm{ml}$ of OLZ and ARP, both.

Preparation of synthetic mixture solution

For analysis of synthetic mixture, the powder of $10 \mathrm{mg}$ OLZ and $10 \mathrm{mg}$ APR was taken, dissolved in $100 \mathrm{ml}$ volumetric flask and made up to $100 \mathrm{ml}$ with methanol. The solution was sonicated for $15 \mathrm{~min}$ and 
filtered through Whatman filter paper No 41. From a clear solution, further dilutions were made to get $10 \mu \mathrm{g} / \mathrm{ml}$ of OLZ and APR, both.

\section{Selection of detection wavelength}

For the selection of wavelength, spectra of both the drug were taken in the HPLC grade methanol, and then drug solutions were scanned in 200-400 $\mathrm{nm}$ region and the spectrum was recorded to get maximum absorbance of analyte in the mobile phase.

\section{Selection of mobile phase}

Mostly selection of mobile phase was based upon good resolution, less symmetric factor, and theoretical plates $(\geq 2000)$. Therefore, the number of trial was taken for the selection of the mobile phase

\section{Preparation of phosphate buffer solution (pH 3)}

Dissolve $3.4 \mathrm{~g}$ of potassium dihydrogen orthophosphate and $2 \mathrm{ml}$ of triethylamine in $800 \mathrm{ml}$ of water adjust the $\mathrm{pH} 3$ with orthophosphoric acid and add sufficient water to produce $1000 \mathrm{ml}$ with distilled water.

\section{Preparation of mobile phase}

Mobile phase was prepared by mixing $75 \mathrm{ml}$ of methanol with $25 \mathrm{ml}$ of $25 \mathrm{mM}$ phosphate buffer having $\mathrm{pH} 3$ mixed well and sonicated. Then, the mobile phase is filtered with a $0.45 \mu \mathrm{m}$ membrane filter.

\section{Optimized chromatographic condition}

The chromatographic condition for the estimation of both the drug is:

1. Stationary phase: Phenomenex C18 column $(250 \mathrm{~mm} \times 4.6 \mathrm{~mm}$ i.d., particle size $5 \mu \mathrm{m}$ )

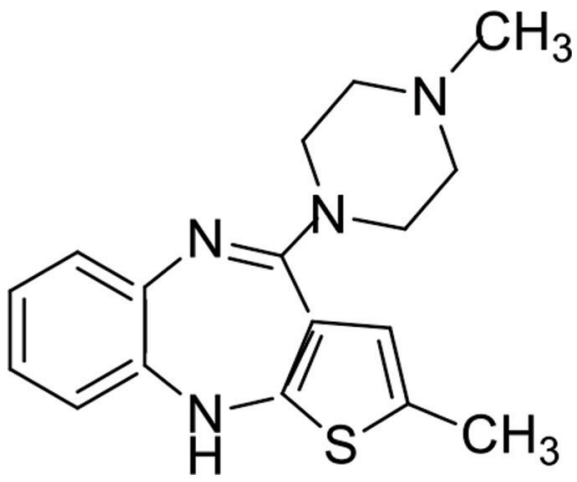

Fig. 1: Chemical structure of olanzapine<smiles>O=C1CCc2ccc(OCCCCN3CCN(c4cccc(Cl)c4Cl)CC3)cc2N1</smiles>

Fig. 2: Chemical structure of aripiprazole
2. Column temperature: Room temperature

3. Mobile phase: Methanol:phosphate buffer $(\mathrm{pH} 3)(75: 25 \% \mathrm{v} / \mathrm{v})$

4. Flow rate: $1.0 \mathrm{ml} / \mathrm{min}$

5. Injection volume: $20 \mu \mathrm{l}$

6. Detection: UV detector SPD-20A at $240 \mathrm{~nm}$

7. Run time: $10 \mathrm{~min}$.

\section{Method validation}

The developed method was validated according to ICH (Q2B) guideline for parameters such as accuracy, precision, specificity, system suitability, limit of detection (LOD), limit of quantification (LOQ), and robustness.

\section{System suitability}

The values for evaluation of system suitability of chromatographic procedure are relative standard deviation (RSD) $<2 \%$, tailing factor $<1.5$, and theoretical plates $>2000$. The retention time, resolution, theoretical plates, and tailing factor were evaluated for the system.

\section{Linearity}

Fresh aliquots were prepared from the stock solution of OLZ and APR $(100 \mu \mathrm{g} / \mathrm{ml})$ ranging from of 0.5 to $3.0 \mu \mathrm{g} / \mathrm{ml}$ for both OLZ and APR, and they were transferred into $10 \mathrm{ml}$ volumetric flask and diluted up to $10 \mathrm{ml}$ using methanol as a solution. The peak area of the solution was then measured at $240 \mathrm{~nm}$. The calibration curve was constructed by plotting peak area versus concentration and the regression coefficient equation was calculated.

\section{Precision}

Repeatability

Six replicates of OLZ $(2 \mu \mathrm{g} / \mathrm{ml})$ and APR $(2 \mu \mathrm{g} / \mathrm{ml})$ were prepared and peak area was calculated at OLZ and APR, respectively, without altering the parameters of the proposed method. The result reported in terms of (\%RSD).

\section{Intermediate precision}

It can be assessed by intraday and interday analysis. The intra-day study was performed by analyzing the three different concentrations of drug for three times in the same day. Inter-day precision was performed by analyzing three different concentrations of the drug for three different days. Different concentrations of the standard solution of OLZ and APR $(1,1.5$, and $2 \mu \mathrm{g} / \mathrm{ml})$ were measured for intraday and interday. The result was reported in terms of (\%RSD).

Accuracy

The accuracy studies were carried out by spiking of the standard at three different concentrations, that is, $50 \%, 100 \%$, and $150 \%$. The recovery studies were carried out by adding a known amount of standard solution of three different levels. Accuracy was carried out by calculating recovery of OLZ and APR by standard addition method, from working sample solution of test $0.5 \mathrm{ml}$ was taken for OLZ and APR and increasing aliquots of working standard solution $0.25 \mathrm{ml}, 0.50 \mathrm{ml}$, and $0.75) \mathrm{ml}$ from $100 \mu \mathrm{g} / \mathrm{ml}$ of OLZ and APR, were added and diluted up to $50 \mathrm{ml}$ with methanol. These solutions were set in triplicate. Peak area of OLZ and APR was measured at a selected wavelength for OLZ and APR. The amount of OLZ and APR was calculated at each level \% recoveries were computed.

Table 1: System suitability parameters of OLZ and APR

\begin{tabular}{|c|c|c|c|c|c|}
\hline \multirow[t]{2}{*}{ Parameters } & \multicolumn{2}{|c|}{ Observed results $\pm S D(n=6)$} & \multicolumn{2}{|c|}{$\%$ RSD } & \multirow[t]{2}{*}{ Acceptance criteria } \\
\hline & OLZ & APR & OLZ & APR & \\
\hline Retention time (Rt) (min) & $4.23 \pm 0.04$ & $6.572 \pm 0.02$ & 0.10 & 0.39 & $\% \mathrm{RSD}<2$ \\
\hline Theoretical plates (N) & $7328.66 \pm 26.25$ & $4851.33 \pm 13.05$ & 0.14 & 0.26 & $>2000$ \\
\hline Tailing factor $(\mathrm{N})$ & $1.49 \pm 0.004$ & $1.37 \pm 0.005$ & - & - & $\mathrm{T} \leq 1.5$ \\
\hline Resolution (Rs) & $9.92 \pm 0.15$ & & 0.29 & & $>2$ \\
\hline
\end{tabular}

OLZ: Olanzapine, APR: Aripiprazole, RSD: Relative standard deviation 


\section{Specificity}

Specificity is the ability to assess unequivocally the analyte in the presence of components that may be expected to be present. Typically, these might include impurities and degradants. A solution of placebo in mobile phase was prepared and injected. The chromatogram of placebo was compared with those acquired from OLZ and APR $(2 \mu \mathrm{g} /$ $\mathrm{ml}$ ) standards, correlation terms of interference at retention time and peak area was evaluated to indicate the specificity of methanol.

\section{$L O D$ and $L Q C$}

LOD and LOQ were calculated from the data obtained from the linearity studies. The slope of the linearity plot was determined. For each of the three replicate determinations, $y$ intercept was calculated and the standard deviation of the y intercept was computed. From these values, the parameters LOD and LOQ were determined on the basis of the response and slope of the regression equation.

LOD and LOQ were calculated by application of the following formula:

$\mathrm{LOD}=3.3 \sigma / \mathrm{S}$

$\mathrm{LOQ}=10 \sigma / \mathrm{S}$

Where, $\sigma=$ standard deviation of response

$\mathrm{S}=$ slope of calibration curve

\section{Robustness}

Robustness was performed by deliberate changes in method parameters such as flow rate, detection wavelength on assay of the analyte of interest. Here, the mobile phase composition varied $\pm 2 \mathrm{~nm}$, flow rate varied $\pm 1.0 \mathrm{ml}$, and $\mathrm{pH}$ varied \pm 0.2 .

\section{RESULTS}

\section{System suitability}

System suitability was checked by repeated preparations of $2 \mu \mathrm{g} / \mathrm{ml}$ of OLZ and APR, both. The typical values for evaluating system suitability of a chromatographic procedure are RSD $<2 \%$, tailing factor $<1.5$ and theoretical plates $>2000$. The retention time, peak area, theoretical plates, and tailing factor were evaluated for the system suitability data of OLZ and APR, the data are shown in Table 1 and Fig. 3.

\section{Linearity}

The linearity in chromatographic methods was good in the range of 0.5-3.0 $\mu \mathrm{g} / \mathrm{ml}$ for OLZ and APR was shown in Figs. 4-6. The correlation coefficient value can be finding out by the regression equation. Correlation coefficient values for OLZ and APR are 0.999 and 0.999 for respectively.

Precision

Repeatability

The precision of the method was checked by repeated preparation $(\mathrm{n}=6)$ of $2 \mu \mathrm{g} / \mathrm{ml}$ of OLZ and APR, both. The \%RSD was found to be $<2 \%$ showing good repeatability. The values for OLZ and APR are shown in Table 2 .

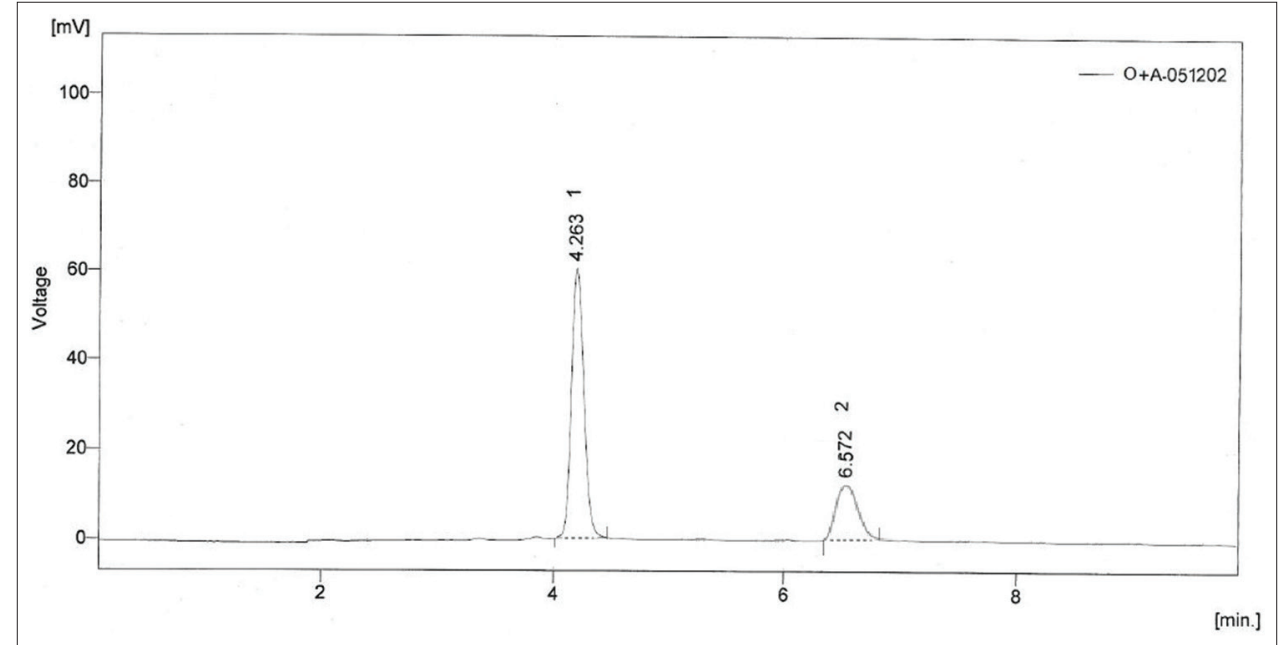

Fig. 3: Optimized chromatographic chromatogram of olanzapine (OLZ) $(2 \mu \mathrm{g} / \mathrm{ml})$ and aripiprazole (APR) $2(2 \mu \mathrm{g} / \mathrm{ml})(\mathrm{peak} 1 \mathrm{oLZ}$ and 2 APR)

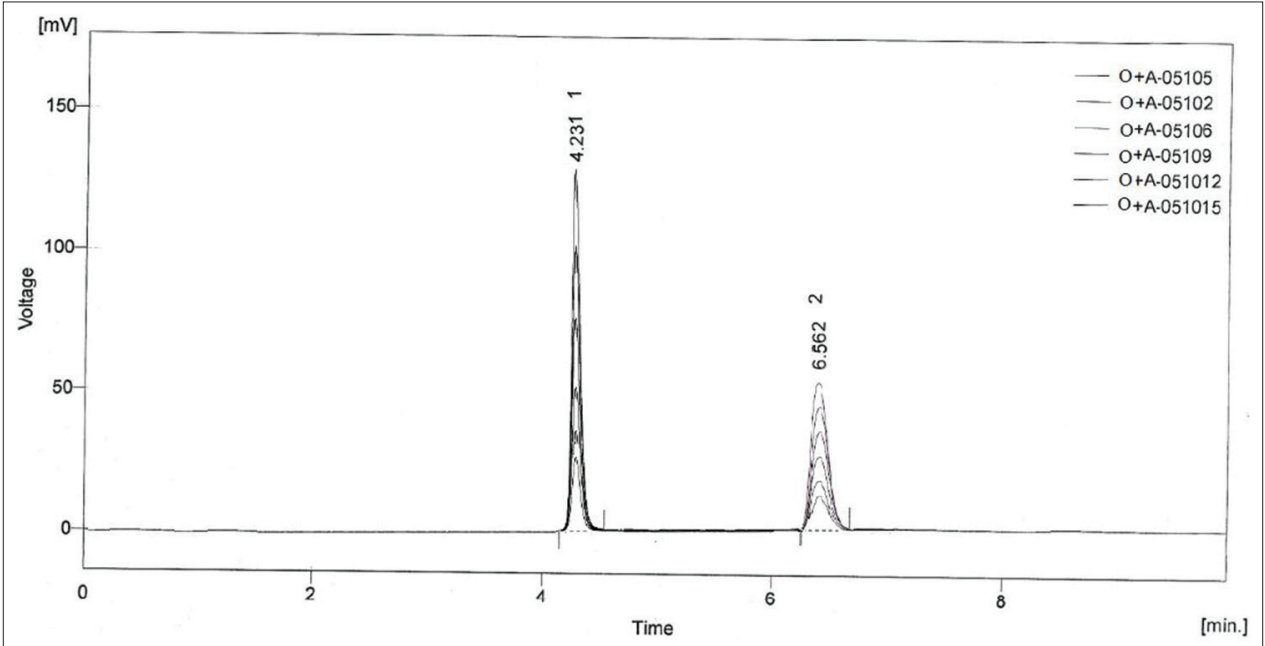

Fig. 4: Chromatogram of linearity (olanzapine [OLZ] and aripiprazole [APR]) using the optimized protocol (peak 1 OLZ and 2 APR) 
Intermediate precision

The low \%RSD value of intraday and interday was established to be (0.15-0.49 and 0.11-0.41) for OLZ and (0.34-0.70 and 0.28-0.42) APR, respectively, reveals that the intended method is precise (Table 3 ).

\section{LOD and LOQ}

LOD was found to be $0.021 \mu \mathrm{g} / \mathrm{ml}$ and $0.065 \mu \mathrm{g} / \mathrm{ml}$ for OLZ and APR and LOQ was found to be $0.13 \mu \mathrm{g} / \mathrm{ml}$ and $0.40 \mu \mathrm{g} / \mathrm{ml}$ for OLZ and APR, respectively.

\section{Accuracy}

The accuracy studies were carried out by spiking of the standard at three different concentrations, that is, $50 \%, 100 \%$, and $150 \%$. The $\%$ recovery study was found out by adding known quantity of standard. Each concentration was analyzed for 3 times and average recovery was calculated. \%Recovery of OLZ and APR was found to be within acceptance criteria, that is, $98-102 \%$ (Table 4).

\section{Specificity}

Mobile phase (methanol) and common excipients such as starch, lactose, and magnesium stearate were dispersed in methanol, filtered, and injected. The chromatogram showed no interfering peaks at the retention time of the two drugs which indicates the specificity of method (Figs. 7-9).

\section{Robustness}

Robustness was performed by deliberate changes in method parameters such as flow rate, detection wavelength on assay of analyte of interest. Here, the mobile phase composition varied $\pm 2 \mathrm{~nm}$, flow rate varied $\pm 1.0 \mathrm{ml}$, and $\mathrm{pH}$ varied \pm 0.2 . The robustness data for OLZ and APR are shown in Table 5. The result indicates that the chosen factors remained unchanged through minute variation in parameters and $\%$ RSD was found which is $<2$; therefore, it reveals that the proposed method is robust in the scenery.

Table 2: Repeatability data of APR and OLZ

\begin{tabular}{|c|c|c|c|c|c|c|c|}
\hline \multicolumn{2}{|c|}{ Conc. $(\mu \mathrm{g} / \mathrm{ml})$} & \multicolumn{2}{|c|}{ Mean of peak area } & \multicolumn{2}{|c|}{ SD $(n=6)$} & \multicolumn{2}{|c|}{ \% RSD } \\
\hline OLZ & APR & OLZ & APR & OLZ & APR & OLZ & APR \\
\hline 2 & 2 & 2542.51 & 845.21 & 25.20 & 4.09 & 0.99 & 0.48 \\
\hline 2 & 2 & 2530.12 & 845.23 & & & & \\
\hline 2 & 2 & 2545.36 & 847.56 & & & & \\
\hline 2 & 2 & 2515.23 & 848.21 & & & & \\
\hline 2 & 2 & 2525.63 & 845.26 & & & & \\
\hline 2 & 2 & 2587.23 & 836.84 & & & & \\
\hline
\end{tabular}

OLZ: Olanzapine, APR: Aripiprazole, RSD: Relative standard deviation
Applicability to synthetic mixtures

Applicability of the proposed RP-HPLC method was tested by analyzing the synthetic mixture (Table 6).

\section{DISCUSSION}

All the method validation parameters were well within the limits, as specified in the ICH Q2B guidelines. Moreover, the \% RSD (less variation) showed good precision of developed method. The calculated LOQ and LOD concentrations confirmed that the methods were sufficiently sensitive. Various system suitability parameters are shown which show that the method is simple, accurate rapid, and precise. The method was

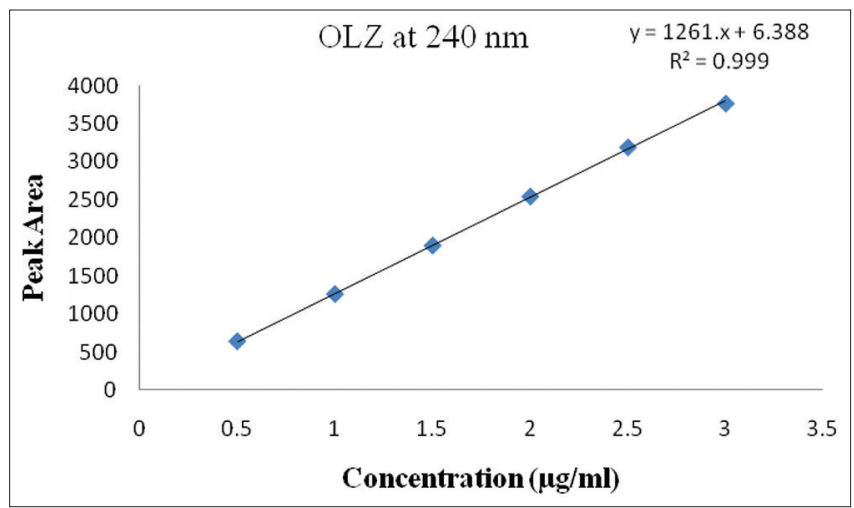

Fig. 5: Calibration curve of olanzapine $(0.5-3.0 \mu \mathrm{g} / \mathrm{ml})$

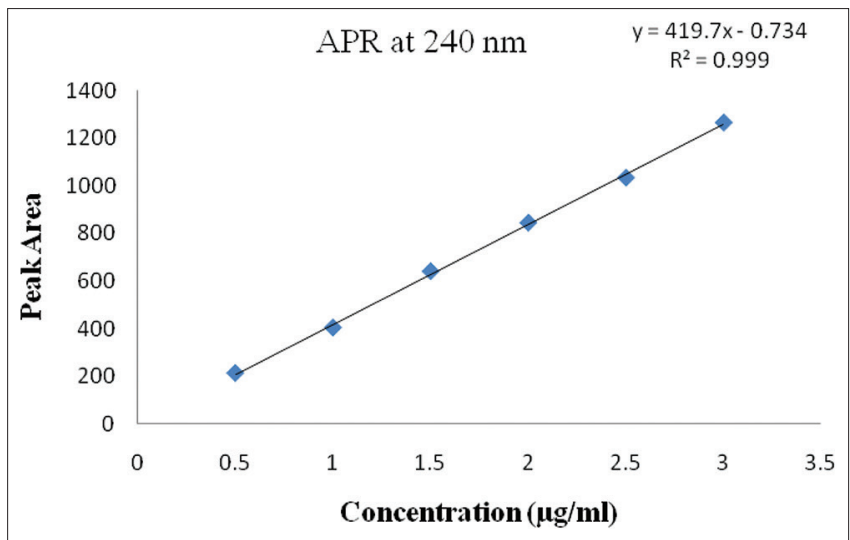

Fig. 6: Calibration curve of aripiprazole $(0.5-3.0 \mu \mathrm{g} / \mathrm{ml})$

Table 3: Intraday and interday precision of OLZ and APR

\begin{tabular}{|c|c|c|c|c|c|c|c|c|c|}
\hline \multicolumn{2}{|c|}{ Concentration $(\mu \mathrm{g} / \mathrm{ml})$} & \multicolumn{2}{|c|}{ Mean of peak area $\pm S D(n=3)$} & \multicolumn{2}{|c|}{ \%RSD } & \multicolumn{2}{|c|}{ Mean of peak area $\pm S D(n=3)$} & \multicolumn{2}{|c|}{ \%RSD } \\
\hline OLZ & APR & OLZ & APR & OLZ & APR & OLZ & APR & OLZ & APR \\
\hline 1 & 1 & $1257.73 \pm 2.67$ & $402.92 \pm 2.65$ & 0.21 & 0.65 & $1255.02 \pm 2.82$ & $401.25 \pm 1.15$ & 0.22 & 0.28 \\
\hline 1.5 & 1.5 & $1895.31 \pm 3.02$ & $640.53 \pm 2.20$ & 0.15 & 0.34 & $1893.85 \pm 2.18$ & $639.28 \pm 2.34$ & 0.11 & 0.36 \\
\hline 2 & 2 & $2527.07 \pm 12.39$ & $843.98 \pm 5.91$ & 0.49 & 0.70 & $2524.29 \pm 10.59$ & $841.74 \pm 3.61$ & 0.41 & 0.42 \\
\hline
\end{tabular}

OLZ: Olanzapine, APR: Aripiprazole, RSD: Relative standard deviation

Table 4: Results of accuracy study of OLZ and APR

\begin{tabular}{|c|c|c|c|c|c|c|c|}
\hline Drugs & Level (\%) & $\begin{array}{l}\text { Amount present } \\
(\mu \mathrm{g} / \mathrm{ml})\end{array}$ & $\begin{array}{l}\text { Amount added } \\
(\mu \mathrm{g} / \mathrm{ml})\end{array}$ & $\begin{array}{l}\text { Total amount of drug } \\
(\mu \mathrm{g} / \mathrm{ml})\end{array}$ & $\begin{array}{l}\text { Amount found } \\
(\mu \mathrm{g} / \mathrm{ml})\end{array}$ & $\begin{array}{l}\% \text { Recovery } \pm S D \\
(n=3)\end{array}$ & $\%$ RSD \\
\hline \multirow[t]{3}{*}{ OLZ } & 50 & 1 & 0.5 & 1.5 & 1.49 & $99.80 \pm 0.13$ & 0.13 \\
\hline & 100 & & 1 & 2 & 2.01 & $100.66 \pm 0.05$ & 0.05 \\
\hline & 150 & & 1.5 & 2.5 & 2.52 & $100.89 \pm 0.09$ & 0.09 \\
\hline \multirow[t]{3}{*}{ APR } & 50 & 1 & 0.5 & 1.5 & 1.52 & $101.82 \pm 0.19$ & 0.19 \\
\hline & 100 & & 1 & 2 & 2.01 & $100.93 \pm 0.30$ & 0.30 \\
\hline & 150 & & 1.5 & 2.5 & 2.46 & $98.74 \pm 0.51$ & 0.52 \\
\hline
\end{tabular}

OLZ: Olanzapine, APR: Aripiprazole, RSD: Relative standard deviation 
Table 5: Robustness study of OLZ and APR

\begin{tabular}{|c|c|c|c|c|c|c|c|c|}
\hline \multirow[t]{2}{*}{ S. No. } & \multirow[t]{2}{*}{ Parameters } & \multirow[t]{2}{*}{ Variation } & \multicolumn{2}{|c|}{ Mean Area } & \multicolumn{2}{|c|}{ Retention time (min) } & \multicolumn{2}{|c|}{ Tailing factor } \\
\hline & & & OLZ & APR & OLZ & APR & OLZ & APR \\
\hline \multirow[t]{3}{*}{1.} & Flow rate $(1 \pm 0.2 \mathrm{ml} / \mathrm{min})$ & 0.8 & 1252 & 402 & 3.68 & 5.00 & 1.52 & 1.25 \\
\hline & & 1.0 & 1305 & 417 & 3.72 & 5.23 & 1.49 & 1.34 \\
\hline & & 1.2 & 1310 & 428 & 3.72 & 5.23 & 1.32 & 1.38 \\
\hline \multirow[t]{3}{*}{2.} & Mobile phase $(75: 25 \% \mathrm{v} / \mathrm{v} \pm 2)$ & $73: 27$ & 1238 & 384 & 3.83 & 5.07 & 1.40 & 1.31 \\
\hline & & $75: 25$ & 1282 & 413 & 3.75 & 5.10 & 1.40 & 1.64 \\
\hline & & $77: 23$ & 1365 & 423 & 3.71 & 5.18 & 1.43 & 1.71 \\
\hline \multirow[t]{3}{*}{3.} & $\mathrm{pH} \pm 0.2$ & 2.8 & 1164 & 387 & 3.59 & 5.15 & 1.28 & 1.41 \\
\hline & & 3 & 1235 & 420 & 3.60 & 5.22 & 1.48 & 1.40 \\
\hline & & 3.2 & 1268 & 426 & 3.62 & 5.24 & 1.57 & 1.48 \\
\hline
\end{tabular}

OLZ: Olanzapine, APR: Aripiprazole

Table 6: Assay result of synthetic mixtures

\begin{tabular}{lllll}
\hline Synthetic mixture & Drug & Amount taken in synthetic mixture & Amount found $(\mathbf{m g}) \mathbf{n}=\mathbf{3} \pm$ SD & \% Amount obtained \pm SD \\
\hline & OLZ & $10 \mathrm{mg}$ & $9.97 \pm 0.17$ & $99.70 \pm 0.75$ \\
& APR & $10 \mathrm{mg}$ & $9.93 \pm 0.85$ & $99.36 \pm 1.02$ \\
\hline
\end{tabular}

OLZ: Olanzapine, APR: Aripiprazole

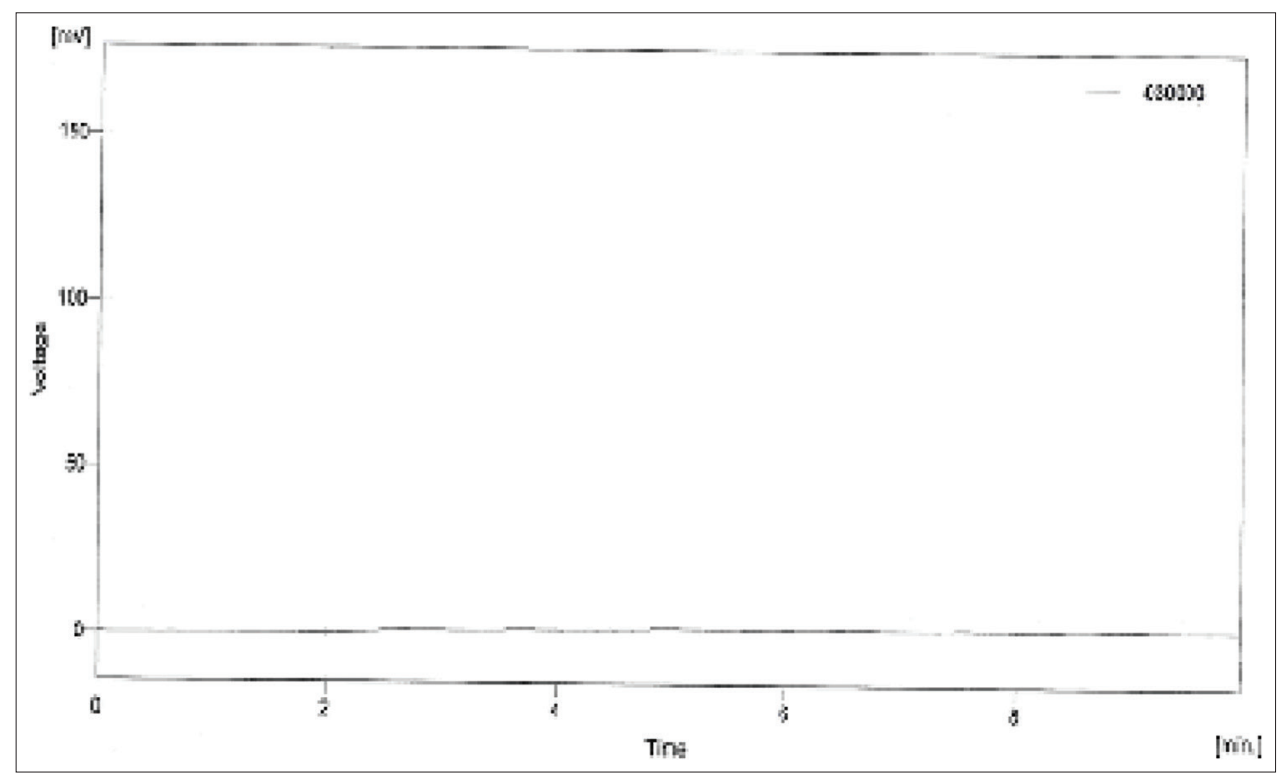

Fig. 7: Chromatogram of blank using optimized conditions

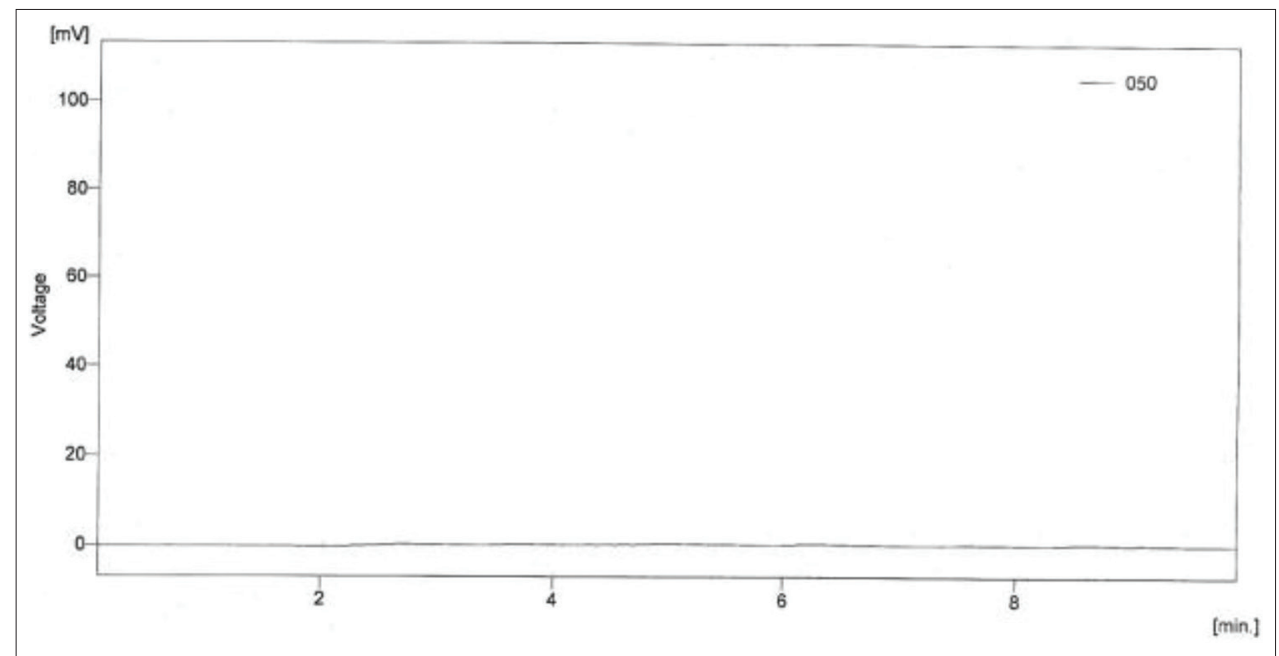

Fig. 8: Chromatogram of excipient using optimized conditions 


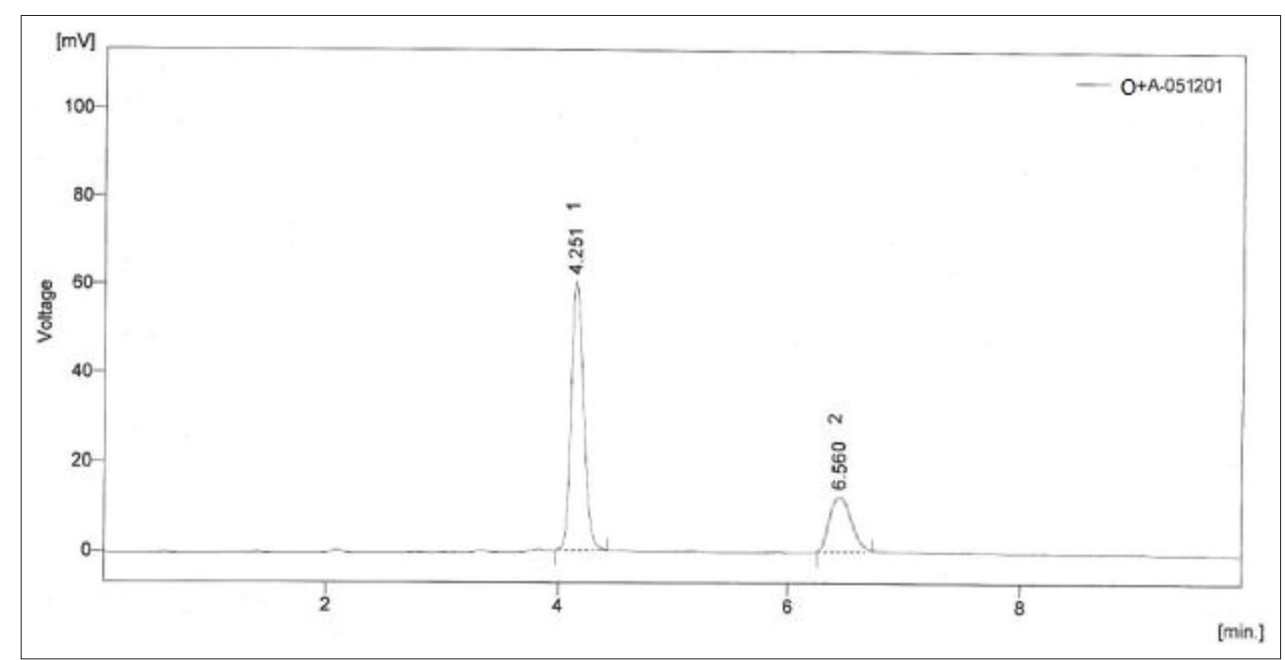

Fig. 9: Chromatogram of binary mixtures (olanzapine + aripiprazole)

suitably employed for assaying all the drugs in commercial marketed formulation. Hence, the developed can be used for further studies, and it helps researches to determine the drug content in formulations as well as in synthetic mixtures.

\section{CONCLUSION}

From the experimental result and parameters, it was concluded that this newly developed method for OLZ and APR was found to be simple, precise, accurate, and high resolution and shorter retention time makes the method more acceptable and cost-effective, and it can be effectively applied for routine analysis in research institution, quality control department, and approved testing laboratories.

\section{AUTHORS' CONTRIBUTIONS}

Ms. Megha has generated the research idea and interpreted the data and draft the manuscript, check plagiarism, and submitting the manuscript. Dr. Paresh Patel has suggested the research idea and participated in the design of the study. Dr. Dhara Patel has participated in the research idea and reviewed the manuscripts.

\section{CONFLICTS OF INTEREST}

The authors confirm that this article content has no conflicts of interest.

\section{AUTHORS' FUNDING}

None.

\section{REFERENCES}

1. Freudenreich O, Goff DC. Antipsychotic combination in schizophrenia. A review of efficacy and risks of current combinations. Acta Psychiatr Scand 2002;106:323-30

2. Kapur S, Zipursky RB, Remington G, Jones C, DaSilva J, Wilson AA, et al. 5-HT2 and D2 receptor occupancy of olanzapine in schizophrenia: A PET investigation. Am J Psychiatry 1998;155:921-8.

3. Yokoi F, Grunder G, Biziere K, Stephane M, Dogan AS, Dannals RF, et al. Dopamine D2 and D3 receptor occupancy in normal humans treated with the antipsychotic drug aripiprazole (OPC 14597): A study using positron emission tomography and [11C] raclopride. Neuropsychopharmacology 2002;27:248-59.

4. Moore H, West AR, Grace AA. The regulation of forebrain dopamine transmission: Relevance to the pathophysiology and psychopathology of schizophrenia. Biol Psychiatry 1999;46:40-55.

5. Millan MJ, Gobert A, Newman-Tancredi A, Lejuene F, Cussac D, Rivet JM. S33084, a novel, potent, selective, and competitive antagonist at dopamine D3-receptors: I. Receptor, electrophysiological and neurochemical profile compared with GR218, 231 and L741, 626. J Pharmacol Exp Ther 2000;293:1048-62.

6. Drug Profile of Olanzapine. Available from: https://www.pubchem.ncbi.
nlm.nih.gov/compound/Olanzapine. [Last accessed on 2018 Jan 21].

7. Drug Profile of Aripiprazole. Available from: https://www.pubchem.ncbi. nlm.nih.gov/compound/aripiprazole. [Last accessed on 2018 Jan 21].

8. Krebs A, Starczewska B, Puzanowska-Tarasiewicz H, Ïled J. Spectrophotometric determination of olanzapine by its oxidation with N-bromo succinimide and cerium (IV) sulphate. Anal Sci 2006;22:829-33.

9. Pradhan KS, Kumari S, Samanta RR. Development and validation of a stability indicating UV spectroscopic method for olanzapine in bulk and pharmaceutical dosage forms. Int J Pharm Pharm Sci 2014;6:67-72.

10. Firdous S, Aman T, Nisa AU. Determination of olanzapine by UV spectrophotometry and non-aqueous titration. Chem Soc Pak 2005;27:163-7.

11. Prasad KV, Kumar JM, Reddy MV, Prabhakar G, Sankar DG. Spectrophotometric determination of olanzapine in pharmaceutical preparations. Asian J Chem 2003;15:1127-30.

12. Sankar DG, Kumar JM, Latha PV. Spectrophotometric estimation of sisomicin and olanzapine. Asian J Chem 2005;17:1331-33.

13. Zhou Z, Li X, Li K, Xie Z, Cheng Z, Peng W, et al. Simultaneous determination of clozapine, olanzapine, risperidone and quetiapine in plasma by high-performance liquid chromatography-electrospray ionization mass spectrometry. J Chromatogr B Analyt Technol Biomed Life Sci 2004;802:257-62.

14. Bogusz MJ, Kruger KD, Maier RD, Erkwoh R, Tuchtenhagen F. Monitoring of olanzapine in serum by liquid chromatographyatmospheric pressure chemical ionization mass spectrometry. J Chromatogr B 1999;732:257-69.

15. Rani AP, Sekaran B. Development of HPLC method for the determination of olanzapine in bulk and dosage forms. J PharmTech Res 2009; 1:654-57.

16. Minase AS, Dole MN, Sawant SD. Development and validation of analytical method for simultaneous estimation of cilnidipine and olmesartan medoxomil in bulk and T dosage form by RP-HPLC. Int $\mathrm{J}$ Pharm Pharm Sci 2014;6:508-11.

17. Raggi MA, Casamenti G, Mandrioli R, Izzo G, Kenndler E. Quantitation of olanzapine in its metabolites by HPLC, CZE, derivative spectrometry and linear voltammetry. J Pharm Biomed Anal 2000;23:973-81.

18. Elian AA. Fatal overdose of olanzapine. Forensic Sci Int 1998;91:231.

19. Zhang M, Jia J, Chuan LU. Development and validation of a liquid chromatography-isotope dilution tandem mass spectrometry for determination of olanzapine in human plasma and its application to bioavailability study. Acta Pharm Sin 2010;45:767-71.

20. Raja A, Venkateshwar RJ. Development and validation of new RPUPLC method for the quantitative determination of olanzapine in tablet dosage form. Asian J Pharm Clin Res 2013;6:178-81.

21. Rao DV, Shetty S, Satheesh K, Radhakrishnanand P, Himabindu V. A stability indicating RPLC method for aripiprazole. Indian J Anal Chem 2008; 7:444-53.

22. Kumar MV, Muley PR. Determination of aripiprazole in bulk drug and solid dosage forms by RP-HPLC method. Indian Pharm 2005;4:71-5.

23. Koduri SV, Buchireddy SR, Madhusudhan G, Mukkanti K, Srinivasulu P. Stress degradation studies on aripiprazole and development of a validated 
stability indicating LC method. Chromatographia 2008;68:635-40.

24. Liu H, Jiang Y, Hao X. Determination of aripiprazole by nonaqueous reversed-phase high performance liquid chromatography. Se $\mathrm{Pu}$ 2005;23:563.

25. Sastry BS, Gananadhamu S, Devala RG. RP-HPLC determination of aripiprazole in pharmaceutical formulations. Asian $\mathrm{J}$ Chem 2009;21:6643-46.

26. Kirschbaum KM, Muller MJ, Zernig G. Therapeutic monitoring of aripiprazole by HPLC with column-switching and spectrophotometric detection. Clin Chem 2005;51:1718-21.

27. Lancelin F, Djebrani K, Tabaouti K, Kraoul L, Brovedani S, Paubel $\mathrm{P}$, et al. Development and validation of a high-performance chromatography method using diode array detection for the simultaneous quantification of aripiprazole and dehydro-aripiprazole in human plasma. J Chromatogr B 2008;867:15-9.
28. Musenga A, Saracino MA, Spinelli D, Rizzato E, Boncompagni G, Kenndler E, et al. Analysis of the recent antipsychotic aripiprazole in human plasma by capillary electrophoresis and high-performance liquid chromatography with diode array detection. Anal Chim Acta 2008;612:204-21.

29. Shimokawa Y, Akiyama H, Kashiyama E, Koga T, Miyamoto G. High performance liquid chromatographic methods for the determination of aripiprazole with ultraviolet detection in rat plasma and brain: Application to the pharmacokinetic study. J Chromatogr B Analyt Technol Biomed Life Sci 2005;821:8-14.

30. Zuo XC, Wang F, Xu P, Zhu RH, Li HD. LC-ESI-MS for rapid and sensitive determination of aripiprazole in human plasma. Chromatographia 2006;64:387-91.

31. International Conference on Harmonization. Q2B Validation of Analytical Procedures: Methodology. Geneva: IFPMA; 1996. 